NEWS ANALYSIS

\title{
Covid-19: What have we learnt about the new variant in the UK?
}

The new SARS-CoV-2 variant has evoked scenes reminiscent of the early days of covid-19 when much of the world banned travel to and from Wuhan, China. With large parts of south-east England locked down, Elisabeth Mahase looks at what we know so far

\section{Elisabeth Mahase}

\section{Is the new variant more infectious?}

Yes, according to a review of the current evidence by the UK's New and Emerging Respiratory Virus Threats Advisory Group (NERVTAG). Its 18 December report said that the rate of transmission of the variant, known as B.1.1.7 or VUI 202012/01 (variant under investigation, year 2020, month 12, variant 01), was $71 \%$ (95\% confidence interval $67 \%$ to $75 \%$ ), higher than for other variants, and that it may also have a higher viral load. ${ }^{1}$ While previous variants have emerged without clear evidence of having a selective advantage, the report noted, the "emergence and subsequent dominance" of this new variant in a period of relatively high prevalence indicated that it does have a "selective advantage over other variants."

\section{When did the new variant appear?}

The first known case of this new variant was recorded on 20 September and sequenced in early October. ${ }^{2}$

\section{How long has the government known about it?}

There has been much speculation over how long the government has known about the new variant and whether it should have acted sooner. Speaking at a Science Media Centre briefing on 21 December, the epidemiologist Susan Hopkins, from Public Health England, said it became clear that this variant was important only in December.

“The [SARS-CoV-2] virus mutates all the time," she said. "Even by March there were eight major lineages that were all separating. Monitoring virus mutations is how we create the genetic family tree of viruses and how we track outbreaks.

"In this situation, towards the end of November it was clear that the Kent and Medway region of the country in particular was going against the tide of the national restrictions and was seeing increases, whereas by 20 November almost all other parts of the country started to decline."

Hopkins explained that an initial review looked at whether this increase in Kent was linked to any particular group in the population or workplace outbreaks. When this proved not to be the case, PHE reviewed the genomic epidemiology to look for changes.

“On 8 December they found that there was a particular variant that had some mutations in the spike protein that had emerged quite rapidly and was spreading not only in the southeast but also in parts of London," she said. "So over the following 48 hours they rapidly undertook an investigation looking at the phylogenetic tree and the clinical details of the patients in which the cases had arisen. They wrote an initial paper on 10 December, which was submitted to NERVTAG, and it was that paper that then started the further discussions on further epidemiological modelling and clinical work."

On 18 December more data were provided to the government, and the next day the prime minister announced that large parts of south-east England, including London, would go into tier 4 restrictions and that the relaxation of rules previously announced for Christmas would change.

\section{What mutations does this variant have?}

The new variant is defined by 14 mutations resulting in amino acid changes and three deletions, some of which are believed to influence the virus's transmissibility in humans.

The World Health Organisation has reported that one of the mutations identified ( $\mathrm{N}_{501} \mathrm{Y}$ ) is altering an amino acid within the six key residues in the receptor binding domain. ${ }^{3}$ This same receptor binding domain mutation (N501Y) has also been reported in South Africa $(n=45)$, where it arose independently of the UK variant, and Australia $(n=37)$. Another change of significance is a deletion at position $69 / 70$, which has been found to affect the performance of some diagnostic polymerase chain reaction (PCR) assays that use an S (spike) gene target.

\section{Does it affect testing?}

Potentially, but PCR testing has a safety net. Speaking on the BBC's Today radio news programme, Wendy Barclay, head of the department of infectious disease at Imperial College London, said that PCR testing relied on three different assays. One of those assays detects the S or spike part of the virus. "One of the ways that this [new virus variant] has been picked up is that the S part of the test does not seem to work as well on this variant. This is not a problem in terms of case numbers, because we have two other back-up parts that still detect the virus," she said.

Less is known about the mutations' effect on lateral flow tests, the rapid turnaround tests that are due to be rolled out in schools across England in January. An investigation into this is ongoing. 


\section{Could the new variant affect vaccines?}

The message from experts speaking at a Science Media Centre briefing on covid-19 was that the new variant was unlikely to make vaccines ineffective. Peter Openshaw, past president of the British Society for Immunology and professor of experimental medicine at Imperial College London, who sits on NERVTAG, said, "We know that natural infection or vaccination will produce quite an array of antibody responses. Although it's predicted that some of the mutations that are present in the new variant will affect some of the sites that are recognised by the antibodies, it does not seem likely that it will affect all of them.

"It's clearly important that all of this is tested, and people are working away in the laboratories as we speak to try to get some preliminary answers within the next few days, but it's not quick science. We have to wait until they can grow the virus and test different serums. So this information could come out in the next few weeks.”

\section{Are children more susceptible to the new variant?}

Yes, in comparison with the non-variant virus. Speaking at a press briefing, Neil Ferguson, director of the Medical Research Council's Centre for Global Infectious Disease Analysis at Imperial College London and NERVTAG member, said that during the November lockdown in England there was a "general shift in the distribution of the virus towards children-for both the variant and the non-variant [virus].” This was expected, because of schools remaining open during the lockdown, he said, and among those aged under 15 there were slightly more cases of the variant virus in the community than the non-variant, though not significantly so.

But Barclay, who also sits on NERVTAG, said, “Let's be clear. We're not saying that this is a virus that specifically attacks children or is any more specific in its ability to infect children. But we know that SARS-CoV-2, as it emerged, was not as efficient at infecting children as it was adults. There are many hypotheses [as to why], but one is the expression of the ACE2 receptor that could be different in children. So if the [new variant] virus is having an easier time of finding and entering the cells, then that would put children on a more level playing field, if you like."

\section{Does current PPE protect against it?}

Although this is something that healthcare workers are understandably keen to find out, the government has made no mention of any difference with respect to effectiveness of personal protective equipment. The Doctors' Association UK has written to Matt Hancock, England's health and social care secretary, to highlight its concern over the lack of new PPE guidance in light of the increased transmissibility of the new variant. Zainab Najim, the association's UK secretary and a GP registrar, said, "Without a universal policy to vaccinate frontline, patient facing staff as a priority, and no review of current PPE guidance, we could be facing avoidable staff sickness and absence over the already difficult winter months. We are also concerned that, without escalating the current PPE guidelines, staff themselves will be at risk not only of contracting the virus but passing it onto the vulnerable patient population."

\section{Has the variant spread across the UK?}

The variant is concentrated in the south-east and east of England and emerging hotspots in south Wales and Cumbria. But there are cases of it everywhere in the UK, said members of NERVTAG.

\section{What about outside the UK?}

A handful of countries have confirmed cases of the new variant, including Australia, Denmark, Italy, Iceland, and the Netherlands.

Hopkins said it's likely that many other countries will report cases soon. She said, "I think that it is very likely it emerged here.

However, it's very likely that it is also in other countries, because there has been transport back and forth between many European countries for the last three months."

She added that the UK does more genome sequencing (10\% of testing samples) than any other European country, except for Denmark, so it may take some time to know the extent of the variant's spread. "Denmark probably sequences about 20\% now and increased its sequencing capacity after the mink variant. The majority of other European countries sequence maybe $1 \%$, and often much less than that, and many have no sequencing capacity whatsoever."

\section{How are other countries responding?}

More than 40 countries have stopped all forms of travel to and from the UK to try to reduce the likelihood of the new variant taking hold in their populations. Most notably, France has shut its border with the UK, blocking the transport of goods into and out of the UK through the port of Dover. All mail services to Europe (except for the Republic of Ireland) have also been temporarily suspended.

\section{Could the port closures affect vaccine stocks?}

No, said the transport secretary, Grant Shapps. Speaking to Sky News, he said that disruption in and around the Channel ports in Kent "won't have an impact on the vaccination programme." 4

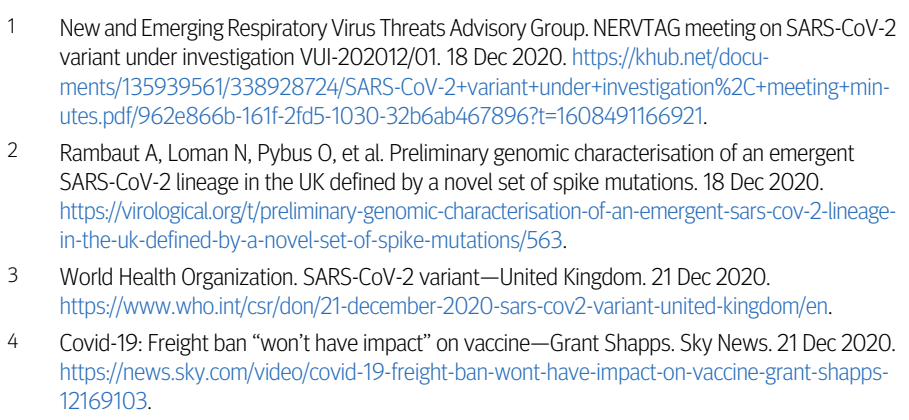

This article is made freely available for use in accordance with BMJ's website terms and conditions for the duration of the covid-19 pandemic or until otherwise determined by BMJ. You may use, download and print the article for any lawful, non-commercial purpose (including text and data mining) provided that all copyright notices and trade marks are retained. 